\title{
Characterisation of four novel fibrillin-1 (FBN1) mutations in Marfan syndrome
}

\author{
Lesley C Adès, Eric A Haan, Alison F Colley, Robert I Richards
}

\begin{abstract}
Forty-four percent of the fibrillin-1 gene (FBN1) from 19 unrelated families with Marfan syndrome was screened for putative mutations by single strand conformational polymorphism (SSCP) analysis. Four novel mutations were identified and characterised in five people, three with classical Marfan syndrome (two from one family, and one from an unrelated family), one with a more severe phenotype, and one with neonatal Marfan syndrome. The base substitutions G2113A, G2132A, $T 3163 G$, and $G 3458 A$ result in amino acid substitutions A705T, C711Y, C1055G, and C1152Y, respectively. C711Y, C1055G, and C1152Y lead to replacement of a cysteine by another amino acid; the latter two occur within epidermal growth factor-like motifs in exon 25 and 27 , respectively. The A705T mutation occurs at exon 16 adjacent to the GT splice site. The A705T and C711Y mutations, at exon 16 and 17, respectively, are the first documented in the second transforming growth factor- $\beta 1$ binding protein-like motif of FBN1. $(\mathcal{M}$ Med Genet 1996;33:665-671)
\end{abstract}

Key words: fibrillin-1 mutations; Marfan syndrome.

Department of Medical Genetics, Centre for Medical Genetics, Women's and Children's Hospital, 72 King William Road, North Adelaide, SA 5006, Australia L C Adès

E A Haan

Hunter Area Regional Genetics Service, PO Box 84, Waratah, NSW 2298, Australia A F Colley

Department of Cytogenetics and Molecular Genetics, Centre for Medical Genetics, Women's and Children's Hospital, 72 King William Road, North Adelaide, SA 5006, Australia R I Richards

Correspondence to: Dr Adès.

Received 4 December 1995 Revised version accepted for publication 20 March 1996 mainly because of cardiovascular complications. Published incidences range between 1 in 5000 and 1 in 10000 live births. ${ }^{2}{ }^{3}$ The phenotype represents a continuum, one end of which merges with the normal population. Mutations in the gene coding for fibrillin-1 on chromosome 15 (FBN1) are responsible for Marfan syndrome, ${ }^{4-6}$ the rare neonatal Marfan syndrome, ${ }^{78}$ and some cases each of autosomal dominant ectopia lentis, ${ }^{7}$ isolated familial aortic aneurysms, ${ }^{9}$ and isolated skeletal features of Marfan syndrome. ${ }^{10}$

Fibrillin is the major structural component of 10-12 nm microfibrils of the extracellular matrix. ${ }^{11}$ It has a highly repetitive structure, including 47 epidermal growth factor (EGF)like motifs, seven cysteine rich transforming growth factor- $\beta 1$ binding protein (TGF- $\beta 1$ BP) motifs, and two hybrid motifs. EGF-like motifs, which comprise the major building blocks of the fibrillin-1 protein, display calcium binding properties. ${ }^{12} 13$ With two exceptions, FBN1 mutations described so far have been unique to each family, occurring randomly over the entire length of the gene. ${ }^{2}{ }^{14}$

We report the clinical features of five Marfan syndrome patients from four families and characterisation of their respective putative FBN1 substitution mutations in the light of current knowledge, with particular reference to genotype-phenotype correlation.

\section{Materials and methods}

THE PATIENTS

The five patients in whom a FBN1 mutation was characterised are described below. None had homocystine in their urine.

\section{Patient 1}

A diagnosis of Marfan syndrome was not suspected in this 31 year old woman until the diagnosis was made in her son (patient 2) at 10 years of age. Although asymptomatic and not considered to have Marfan syndrome on clinical grounds, an echocardiogram confirmed aortic root dilatation and aortic incompetence. Her height was $174.5 \mathrm{~cm}$ (97th centile), arm span $174.5 \mathrm{~cm}$, upper:lower segment ratio 0.97 , and mid-finger and hand lengths $9 \mathrm{~cm}$ and $20.5 \mathrm{~cm}$, respectively (>97th centile). Slit lamp examination showed bilateral lens dislocation. She was treated with propranolol and had regular echocardiographic surveillance. A Bentall's procedure (composite aortic graft repair and aortic valve replacement) was performed at 37 years of age when the aortic root diameter (ARD) was $6 \mathrm{~cm}$.

\section{Patient 2}

The diagnosis of Marfan syndrome was first suspected in this boy at the age of 10 years, because of his high, narrow palate, tall stature, dolichostenomelia, arachnodactyly, thoracic scoliosis, and combined pectus excavatum/ carinatum defect. Echocardiogram showed lapse, and mild mitral incompetence. Slit lamp examination showed bilateral lens dislocation. Radiograph of the spine showed hypoplasia of the posterior elements of $\mathrm{C} 1$. He had limitation of neck extension, progressive contracture of both elbow joints, hypermobility of the distal interphalangeal joints, and fixed flexion deformities of the proximal interphalangeal joints of both index fingers. He required orthodontic treatment, bilateral lens aspiration, and surgery to widen the palate. His clinical phenotype was aortic root dilatation, mild mitral valve pro- 
more severe than that of his mother. At the age of 19 years, his height was $188 \mathrm{~cm}$ (90th-97th centile), upper:lower segment ratio 0.81 , and mid-finger and hand lengths $9.5 \mathrm{~cm}$ and 21.5 $\mathrm{cm}$, respectively ( $>97$ th centile). He had marked striae distensae over the hips, thighs, and lumbar region. There was progressive aortic root dilatation (ARD $4.9 \mathrm{~cm}$; normal $<3.7$ $\mathrm{cm}$ ) and at the age of 21 years, aortic graft surgery is being planned.

\section{Patient 3}

A diagnosis of Marfan syndrome was made at the age of 5 years, based on clinical features of tall stature, myopia, bilateral lens dislocation, a high arched palate, arachnodactyly, and bilateral inguinal herniae. The patient was abroad with his family until the age of 13 years and, on return, echocardiography showed dilatation of the aortic root (ARD 3.4, 3.6 (95th centile 3.2 $\mathrm{cm}$ ) and $3.8 \mathrm{~cm}$ (95th centile $3.6 \mathrm{~cm}$ ), at 13 , 15 , and 16 years of age, respectively). He was treated with atenolol. At the age of 15 years his height was $185 \mathrm{~cm}$ (97th centile), arm span $195 \mathrm{~cm}$, upper:lower segment ratio 0.79 , and mid-finger, hand, and foot lengths $9.8 \mathrm{~cm}, 22.8$ $\mathrm{cm}$, and $31 \mathrm{~cm}$, respectively (>97th centile). Other clinical features included bilateral peripheral retinal degeneration, hypermobility of the distal interphalangeal joints, fixed flexion contractures of the proximal interphalangeal joints of both little fingers, and a combined pectus excavatum/carinatum defect. At 17 years of age, there has been minimal progression of aortic root dilatation, and he remains well.

\section{Patient 4}

This patient, born at term, had the following growth parameters: birth weight (BW) $3130 \mathrm{~g}$ (25th-50th centile), birth length (BL) $47 \mathrm{~cm}$ ( 3 rd centile), and head circumference (HC) $35.5 \mathrm{~cm}$ (50th centile). He had scaphocephaly, facial dysmorphism, pinpoint pupils, marked redundancy of facial skin, generalised hypotonia, camptodactyly of the fingers, and bilateral talipes equinovarus. $\mathrm{He}$ underwent surgical correction of a left undescended testis, bilateral inguinal herniae, and an umbilical hernia at the age of 11 months. Following surgery, a cardiac murmur was heard, and echocardiography confirmed mitral valve prolapse. A cerebral CT scan at 14 months showed early fusion of the metopic suture and dilatation of the lateral and third ventricles, suggesting mild communicating hydrocephalus. The carpal bone age was relatively advanced in relation to the remainder of the hand bones.

At the age of 15 months, $\mathrm{HC}$ was $52.6 \mathrm{~cm}$ (>97th centile) and height $86 \mathrm{~cm}$ (97th centile). He had a ridged metopic suture, deep set eyes, large ears $(6 \mathrm{~cm}$ length, $>97 \mathrm{th}$ centile), micrognathia, and long, slender fingers. There was general redundancy of the skin, normal finger joint mobility, and limited elbow extension and hip abduction. He had normal hearing and delayed speech and motor development. A diagnosis of Weaver syndrome was made, based on the craniofacial structure, congenital camptodactyly, advanced bone age, and rapid growth in the first year of life.

Echocardiography at 3 years of age showed aortic root dilatation and mitral valve prolapse and led to a revised diagnosis of Marfan syndrome. Ophthalmological examination at 4 years confirmed myopic astigmatism and amblyopia of the right eye. The pupils could not be fully dilated because of iris dilator atrophy and, consequently, lens dislocation could not be excluded. He had a lean body build, generalised joint laxity, long narrow feet, and slender fingers. There was an asymmetrical pectus carinatum defect associated with prominence of the sternocostal junction. The accelerated growth had ceased. He was treated with verapamil, as asthma precluded treatment with $\beta$ blockers.

At the age of 6.5 years (fig 1), his $\mathrm{HC}$ was $57.5 \mathrm{~cm}$, height $129.5 \mathrm{~cm}$ (both >97th centile), arm span $131 \mathrm{~cm}$, upper:lower segment ratio 0.96 , mid-finger length $6 \mathrm{~cm}$ (75th centile), and hand and foot lengths $15.4 \mathrm{~cm}$ and 20.5 $\mathrm{cm}$, respectively (both 97 th centile). At 7.5 years of age, the ARD measured $3.4 \mathrm{~cm}$ (95th centile $2.45 \mathrm{~cm}$ ) and psychometric assessment (WISC-III) resulted in an overall score within the average range of intellectual abilities, with verbal expression above average for age.

Since the age of 9 to 10 months, he had episodes of cyanosis, pallor, and nausea with or without vomiting, headache, and sleepiness. Sleep studies at the age of 7 years excluded the possibility of obstructive apnoea. Cardiac re-evaluation could not identify a cause for the episodes, and a follow up CT scan at 8 years

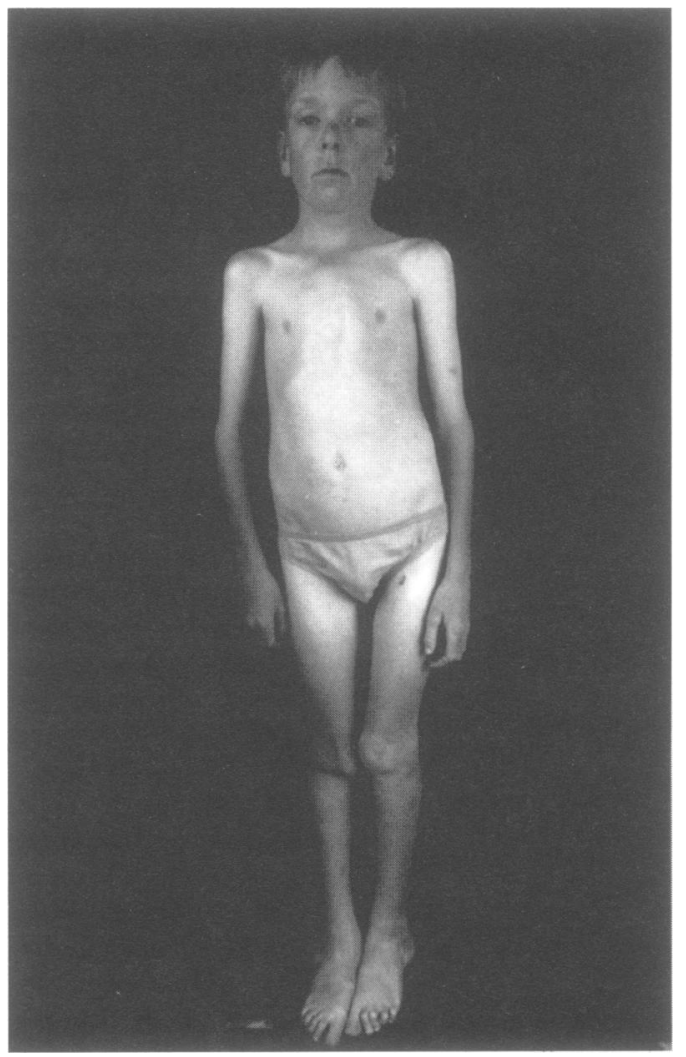

Figure 1 Patient 4 aged 6.5 years. (Photograph reproduced with parental consent.) 


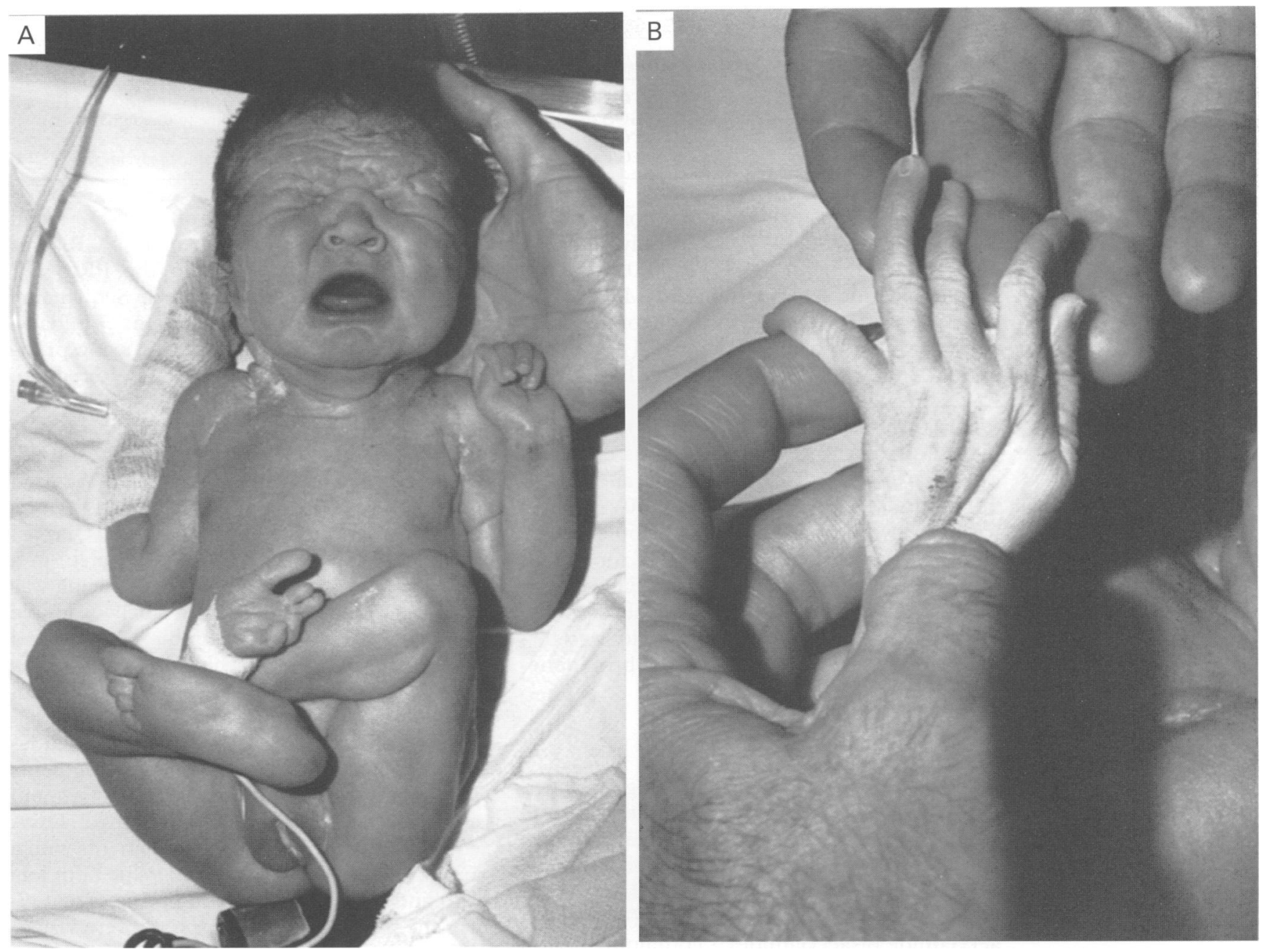

Figure 2 (A) Patient 5 in the newborn period. Note excessive redundant facial skin and long feet and toes. (B) Right hand of patient 5 showing redundant skin, hyperextensibility of the digits, and arachnodactyly. (Photographs reproduced with parental consent.)

was unchanged. He continues to have cyanotic episodes (aetiology unknown) but is otherwise well.

\section{Patient 5}

This baby (fig 2A) was the second child of non-consanguineous parents. Her BW was $3200 \mathrm{~g}$ (50th centile), HC $36.8 \mathrm{~cm}$ (97th centile), and crown-heel length $55 \mathrm{~cm}$ (97th centile), taking limb contractures into consideration. There was a relative lack of subcutaneous fat. The ears were long $(4.5 \mathrm{~cm})$ and soft with hypoplastic cartilage. The limbs were long, there was arachnodactyly (fig 2B), and the hand $(7.5 \mathrm{~cm})$, mid-finger $(3.5 \mathrm{~cm})$, and foot $(9.3 \mathrm{~cm})$ lengths were all greater than the 97th centile. There was ulnar deviation of the fingers, flexion contractures of the shoulders, elbows, hips, knees, and ankles, and camptodactyly and flexion contractures of the toes. The skin was redundant and loose. Ophthalmological examination showed poor dilator muscle of the pupils but no lens dislocation. A chest radiograph showed eventration of the right hemidiaphragm, slender long bones, and gracile ribs. Echocardiogram showed hypokinesia of both ventricles, a flared and mildly dilated aortic root (ARD $1.4 \mathrm{~cm}$ ), a normal aortic valve, prolapse of both mitral valve leaflets, mild mitral regurgitation, and moderate tricuspid valve prolapse with mild regurgita- tion. Cranial ultrasound was normal apart from an enlarged cisterna magna. She died at home (cause unknown) at the age of 2 months with no apparent preceding illness. The parents declined skin biopsy and necropsy.

\section{GENOMIC DNA EXTRACTION AND PCR}

AMPLIFICATION

DNA was extracted from peripheral blood leucocytes from the probands and parents after obtaining informed consent. Genomic DNA samples were amplified by PCR and the products subjected to single strand conformational polymorphism (SSCP) analysis. All PCRs were performed using selected intron based exon specific primers. Primers were designed according to published sequence data. ${ }^{14} \mathrm{~A}$ Perkin-Elmer Cetus DNA thermal cycler was used to individually PCR amplify DNA using primers for the FBN1 exons 15-18 inclusive, 23-32 inclusive, and exon 59. Oligonucleotide primers for exons 23, 24, 27, 29, 30, 31, and 32 were generously provided by the National Marfan Foundation and Dr H C Dietz, and for exons 25 and 26 by Dr D M Milewicz. The remaining primers were synthesised in the Department of Cytogenetics and Molecular Genetics (Adelaide). Reactions were carried out under the following conditions: $100 \mathrm{ng}$ of genomic DNA was amplified in a $10 \mu \mathrm{l}$ volume according to Kogan et $a l,{ }^{15}$ but using 400 
Table 1 Four novel FBN1 gene mutations in Marfan syndrome

\begin{tabular}{llll}
\hline Patient & Location of mutation & Sequence alteration & Amino acid alteration \\
\hline Patients 1 and 2 (classical) & Exon 17 (second TGF- $\beta$ 1 BP motif) & TGC to TAC (nucleotide 2132) & C711Y (cysteine to tyrosine) \\
Patient 3 (classical) & Exon 16 (second TGF- $\beta$ 1 BP motif) & GCG to ACG (nucleotide 2113) & A705T (alanine to threonine) \\
Patient 4 (severe) & Exon 27 (cb-EGF motif) & TGT to TAT (nucleotide 3458) & C1152Y (cysteine to tyrosine) \\
Patient 5 (neonatal) & Exon 25 (cb-EGF motif) & TGT to GGT (nucleotide 3163) & C1055G (cysteine to glycine) \\
\hline
\end{tabular}

$\mu \mathrm{mol} / 1$ of dNTPs, $75 \mathrm{ng}$ of the forward and reverse primers, $0.5 \mathrm{U}$ Taq DNA polymerase (5 $\mathrm{U} / \mu \mathrm{l})$, and $0.3 \mu \mathrm{l}$ of $\alpha^{32} \mathrm{P}-\mathrm{dCTP}(800 \mathrm{Ci} / \mathrm{mmol})$ radionucleotide label. Optimised $\mathrm{MgCl}_{2}$ concentrations for the FBN1 oligonucleotide primers were as follows: $1.5 \mathrm{mmol} / \mathrm{l}$ (exons 15 , $16,25,26,29), 2.5 \mathrm{mmol} / 1$ (exons $18,23,24$, 27), $3 \mathrm{mmol} / \mathrm{l}$ (exons 31, 32, 59), $3.5 \mathrm{mmol} / 1$ (exon 30), $4.0 \mathrm{mmol} / \mathrm{l}$ (exon 17), and 4.5 $\mathrm{mmol} / \mathrm{l}$ (exon 28). PCR incubations consisted of 10 cycles at $94^{\circ} \mathrm{C}$ for 60 seconds, at $60^{\circ} \mathrm{C}$ for 90 seconds, and at $72^{\circ} \mathrm{C}$ for 90 seconds, followed by 25 cycles at $94^{\circ} \mathrm{C}$ for 60 seconds, at $55^{\circ} \mathrm{C}$ for 90 seconds, and at $72^{\circ} \mathrm{C}$ for $90 \mathrm{sec}-$ onds. Samples were stored at $4^{\circ} \mathrm{C}$. Each amplified sample was mixed with an equal volume of formamide loading buffer $(96 \%$ deionised formamide, $10 \mathrm{mmol} / 1 \mathrm{EDTA}, 0.1 \%$ bromophenol blue, $0.1 \%$ xylene cyanol).

SINGLE STRAND CONFORMATIONAL

POLYMORPHISM (SSCP) ANALYSIS

SSCP analysis was performed using amplified DNA fragments. ${ }^{16}$ After denaturation at $96^{\circ} \mathrm{C}$ for five minutes, each sample was snap frozen on ice. Four $\mu$ l of each radiolabelled PCR product were resolved on $4.5 \%$ and $10 \%$ nondenaturing polyacrylamide gels (49:1 ratio acrylamide:bisacrylamide) containing $10 \%$ glycerol. The DNA fragments were analysed by electrophoresis through the gels at 600 volts at room temperature for between eight and 34 hours (dependent on the gel percentage and relative size of exon). Gels were dried on filter paper and exposed to $x$ ray film at $-70^{\circ} \mathrm{C}$ for between six hours and five days. The DNA fragments were visualised on autoradiographs.

Population screening was performed whenever a reproducible band shift was detected by SSCP analysis. In all such cases, genomic DNA from 70 unaffected subjects (140 chromosomes) and, wherever possible, from the affected subject's parents or an unaffected first degree relative, were included in the screening. A band shift was considered representative of a polymorphism if the screening detected similar band shifts in $>1 \%$ of the samples. ${ }^{17}$ Such band shifts were presumed to represent silent polymorphisms within the population and were not investigated further, or characterised by DNA sequencing.

DNA SEQUENCING

For exons 16, 17, and 27 amplified from genomic DNA of patients 3, 1 and 2, and 4 respectively, the DNA fragments were cloned into the pGEM-T vector ( $\mathrm{pGEM}^{\mathbb{R}}-\mathrm{T}$ Vector System I, Promega) and plasmids containing the inserted DNA templates were purified according to the manufacturer's instructions using the plasmid purification protocol and Qiagen columns (Qiagen Plasmid Handbook for Plasmid Mini Kit, 1993). The DNA was quantitated and dilutions of $210-250 \mathrm{ng} / \mu \mathrm{l}$ made in preparation for sequencing PCR. This was carried out according to the PRISM ${ }^{\mathrm{TM}}$ Ready Reaction Dye Primer Cycle Sequencing Kit protocol (Applied Biosystems). Initially, cycle sequencing was undertaken using primers in either the forward or reverse direction. Once a sequence alteration was found, cycle sequencing using the alternate primer was performed to confirm the mutation. For exon 25, the amplified DNA fragment (patient 5) used for direct sequencing was purified using the reagents and protocol of the Qiaquick (Qiagen) PCR Purification Kit Protocol (Bresatec) in a $100 \mu \mathrm{l}$ reaction volume. Cycle sequencing was used to produce fluorescently labelled double stranded PCR product using the reagents and conditions specified in the Taq DyeDeoxy ${ }^{\mathrm{TM}}$ Terminator Cycle Sequencing Kit protocol (Applied Biosystems).

The purified and fluorescently labelled dideoxy terminated or dye primer PCR fragments were separated on a $6 \%$ sequencing gel and sequenced using an $\mathrm{ABI}$ automated DNA sequencer model 373A. DNA fragments with a point mutation were sequenced using both forward and reverse amplification primers to confirm the mutation. Sequence data were visualised as a four colour chromatogram, and then compared to normal FBN1 gene cDNA sequence obtained from Genbank database (Genbank database accession number L13923; complete coding sequence of HUMFIBRILLIN Homo sapiens fibrillin mRNA).

RESTRICTION ENZYME DIGESTION

Pst I enzyme digestion was carried out at $37^{\circ} \mathrm{C}$ for four hours.

\section{Results}

SSCP analysis, and subsequent sequence analysis in both forward and reverse directions of individually amplified exons from the probands' DNA, identified four novel missense FBN1 mutations out of 26 patients from 19 families. Two patients from one family (patients 1 and 2) had the same FBN1 mutation, and three patients (patients 3,4, and 5) had different mutations (table 1). All SSCP band shifts were detected with $10 \%$ polyacrylamide/ glycerol gels, whereas only two of the four band shifts (in DNA from patients 1 and 2) were identified with $4.5 \%$ gels.

C711Y MISSENSE MUTATION: FAMILIAL CLASSICAL MARFAN SYNDROME (PATIENTS 1 AND 2)

Sequence analysis of this $133 \mathrm{bp}$ fragment showed a heterozygous $G$ to A substitution at nucleotide 2132 in exon 17. This substitution predicts a $\mathrm{C} 711 \mathrm{Y}$ missense mutation caused by alteration of the wild type cysteine, an uncharged polar amino acid, to a tyrosine amino 
acid in the second TGF- $\beta 1$ BP-like motif of the fibrillin protein. The normal sequence in this region encodes a PstI enzyme restriction site (recognition sequence 5'...CTGCA $\downarrow$ G....3'; arrow indicates site of enzyme cleavage) and the C711Y mutation was predicted to abolish this site (altered sequence: 5 '...CTCCAG...3') in the mutant allele in affected patients. Exon 17 specific PCR amplification products of genomic DNA from six unaffected subjects and patients 1 and 2 were subjected to restriction digestion with $P s t \mathrm{I}$, and electrophoresed through a $3 \%$ agarose gel stained with ethidium bromide. In unaffected subjects with two intact Pst I sites, Pst I digestion yielded two digested fragments whose sizes ( 57 and $76 \mathrm{bp}$ ) together added up to the size of the undigested PCR product $(133 \mathrm{bp})$. In patients 1 and 2 with the C711Y mutation, the PstI digest showed the three bands predicted, providing further verification of the putative mutation C711Y.

A705T MISSENSE MUTATION: SPORADIC CLASSICAL MARFAN SYNDROME (PATIENT 3) Sequence analysis of this $257 \mathrm{bp}$ fragment showed a heterozygous $\mathrm{G}$ to A single base substitution at nucleotide 2113. This change predicts an A705T missense mutation that alters the wild type alanine (non-polar) to a threonine (uncharged polar) amino acid in the last codon of exon 16, adjacent to the GT splice site. Sequencing of plasmid DNA from the unaffected mother gave normal results.

C1152Y MISSENSE MUTATION: SEVERE MARFAN SYNDROME (PATIENT 4)

Sequence analysis of this $181 \mathrm{bp}$ fragment showed a heterozygous $\mathrm{G}$ to $\mathrm{A}$ single base substitution at nucleotide 3458 (corresponding to amino acid 1152). The $\mathrm{C} 1152 \mathrm{Y}$ missense mutation predicts an alteration of the wild type cysteine amino acid to a tyrosine. Since the patient is adopted, there was no ready recourse to comparative sequence analysis of DNA from the biological parents. However, sequencing from an unaffected control gave normal results.

\section{C1055G MISSENSE MUTATION: NEONATAL}

MARFAN SYNDROME (PATIENT 5)

Direct DNA sequencing and analysis of exon 25 PCR amplified fragments $(273 \mathrm{bp})$ in forward and reverse directions showed a heterozygous $T$ to $G$ single base substitution at nucleotide 3163 , which is predicted to result in a $\mathrm{C} 1055 \mathrm{G}$ substitution in one of the calcium binding (cb)EGF-like domains constituting 12 such consecutive motifs in the central portion of the FBN1 gene. The C1055G substitution alters the wild type cysteine to a glycine amino acid.

\section{Discussion}

We have characterised four novel FBN1 mutations in five Marfan syndrome patients. Two members of a family with classical Marfan syndrome have different disease severity, with the son more severely affected than his mother. A third patient has a classical Marfan phenotype, presumably caused by a de novo FBN1 mutation. These three patients have mutations within the second TGF- $\beta 1$ BP motif of FBN1, a region in which no FBN1 mutations have hitherto been described. The fourth patient manifested clinical features in the neonatal period but it was some years before a correct diagnosis was assigned. The last patient had neonatal Marfan syndrome and died at 2 months of age. These latter two patients, both with severe phenotypes, had a mutation affecting an EGF-like repeat in the central portion of the FBN1 gene.

CLASSICAL MARFAN SYNDROME

Two novel heterozygous mutations, A705T and C711Y, were identified in three patients with classical Marfan syndrome (patients 1, 2, and 3). The A705T and C711Y mutations at exons 16 and 17 , respectively, are the first reported in the second TGF- $\beta 1$ BP motif. There are six other mutations reported in TGF- $\beta 1$ BP motifs of FBN1. The third and fourth TGF- $\beta 1$ BP motifs flank 12 consecutive cb-EGF motifs in the central portion of the FBN1 gene. The mutations G1013R and $\mathrm{K} 1023 \mathrm{~N}$ both occur in the third TGF- $\beta 1 \mathrm{BP}$ motif, corresponding to exon 24 . Both are associated with a severe neonatal phenotype. The C1589F mutation (exon 38) and a $4 \mathrm{bp}$ insertion mutation (exon 41) that leads to a premature termination codon occur in the fourth and fifth TGF- $\beta 1$ BP motifs, respectively, and both are associated with a classical Marfan phenotype. Mutations Y2113X and del ex 51 both occur in the sixth TGF- $\beta 1$ BP motif, corresponding to exon 51, and are associated with classical Marfan syndrome ${ }^{2}$ (FBN1 mutations reported to Marfan syndrome and related disorders research consortium). There are no reported mutations involving the first or last (seventh) TGF- $\beta 1$ BP motifs.

The A705T de novo mutation leads to substitution of a non-polar alanine for an uncharged polar threonine residue in the second TGF- $\beta 1$ BP motif of FBN1. The wild type alanine is located precisely five codons up and downstream from two conserved cysteine residues. This cysteine rich TGF- $\beta 1$ BP domain may participate in protein-protein interactions, and the nature and location of the A705T mutation may be responsible for disrupted domain conformation.

Of the mutations identified in TGF- $\beta 1$ BP motifs, only the $\mathrm{C} 1589 \mathrm{~F}$ and $\mathrm{C} 711 \mathrm{Y}$ alter a wild type cysteine residue. Interestingly, both mutations occur at the same cysteine residue in their respective TGF- $\beta 1$ BP motifs, suggesting that this cysteine may have a critical function within these motifs. The C711Y mutation occurs at the eighth cysteine residue of the second TGF- $\beta 1$ BP motif, while the $\mathrm{C} 1589 \mathrm{~F}$ substitution occurs at the eighth cysteine of the fourth TGF- $\beta 1$ BP-like domain of fibrillin. ${ }^{18}$ The latter patient had congenital contractures but no skeletal or ocular findings, and was diagnosed with Marfan syndrome when he developed aortic root dilatation. Fibrillin protein biosynthesis studies of dermal fibroblasts showed a normal rate of synthesis, delayed 
secretion, and fibrillin deposition into microfibrils of about $65 \%$ of normal. ${ }^{19}$ The familial C711Y mutation is responsible for a classical Marfan phenotype in mother and son. However, the son, with significant pain and limitation of movement of the upper cervical spine, and impending prophylactic aortic graft surgery for progressive aortic root dilatation, is clearly more severely affected than his mother. This illustrates the well recognised intrafamilial variability in Marfan syndrome, despite the presence of an identical FBN1 mutation.

NEONATAL AND SEVERE MARFAN SYNDROME

Two novel mutations were identified, one in a patient with a severe Marfan phenotype (patient 4), and the other in a patient with neonatal Marfan syndrome (patient 5). Interestingly, both patients had iris dilator hypoplasia. Awareness of the association of this congenital finding with Marfan syndrome ${ }^{20}$ may have led to an earlier diagnosis in patient 4 . Patient 5 had eventration of the hemidiaphragm, a feature which has been described only rarely in Marfan syndrome. ${ }^{21}$

Despite a relatively severe phenotype, patient 4 (adopted) has survived beyond the neonatal period. Parental DNA was not available but since neither natural parent is known to have Marfan syndrome (personal communication with natural parents), the possibility that he could represent a compound heterozygote was considered unlikely. There has been one report of a rare compound heterozygote Marfan patient (lethal phenotype), born to non-consanguineous parents with classical Marfan syndrome. ${ }^{22}$ The two characterised FBN1 mutations in that infant show incomplete dominance of FBN1 mutations and this highlights the fact that the normal allele plays a significant role in ameliorating the disease process in Marfan syndrome.

The mutations in patients 4 and 5 occurred in exon 27 and exon 25, respectively. The locations are in keeping with the reported clustering of FBN 1 mutations between exons 24 and 32 in most cases of neonatal Marfan syndrome. $^{7}$ This region codes for the longest uninterrupted stretch of $12 \mathrm{cb}$-EGF domains in the fibrillin polypeptide, and is flanked on either side by the third and fourth TGF- $\beta 1$ BP-like domains. Electron microscope (EM) rotary shadowing studies of microfibrils and pulse chase studies assessing fibrillin processing have shown that cells from all patients studied with neonatal Marfan syndrome produce only disorganised fibrillin aggregates, and no clearly defined microfibrils, suggesting a major role of this polypeptide region in the stabilisation and organisation of microfibrils. ${ }^{23}$

Some mutations causing classical or even mild Marfan syndrome also occur in this region, so the regional location of the mutation cannot be the sole determinant of phenotypic severity. Other factors including the character of the mutation and modifiers of phenotypic expression are also relevant. Mutations in this region that produce premature termination codons are not associated with neonatal Marfan syndrome. There is evidence that mutations that substitute cysteine residues are less likely to cause severe disease than those which alter other residues. ${ }^{14}$ The $\mathrm{C} 1055 \mathrm{G}$ and C1152Y mutations both alter a wild type cysteine, yet each is associated with a severe clinical phenotype. These findings appear contrary to published reports which suggest that, in general, cysteine substitutions cause a severe phenotype only when they occur at the aminoor carboxy-terminus of the FBN1 gene, the proposed sites of nucleation for microfibrillar assembly. ${ }^{214}$ However, it has also been suggested that the location rather than the character of the mutation might be the more influential factor in determining phenotypic severity. ${ }^{714}$ It is probable that mutations in the region between exons 24 and 32, which cause a severe phenotype, can affect the structure of the the fibrillin monomer over a wide distance. One reported mutation in neonatal Marfan syndrome occurs in exon 25 and involves a 3 bp insertion of a cysteine into an EGF domain. ${ }^{8}$ This insertion mutation is located 11 bases (four amino acids) downstream from the substitution mutation C1055G defined in patient 5 . The site of the $\mathrm{C} 1055 \mathrm{G}$ mutation lends further support to the growing evidence for the clustering of neonatal Marfan syndrome mutations in the central portion of the FBN1 gene between exons 24 and 32. The presumed functional significance of this region in terms of microfibrillar organisation, structure, and assembly is further underscored by the disruption of a cysteine residue in a cb-EGF-like domain, in association with a perinatal lethal phenotype in patient 5 .

Four novel FBN1 substitution mutations have been characterised in five Marfan patients of varying phenotypic severity. The familial C711Y mutation and de novo A705T mutation are the first documented in the second TGF- $\beta 1$ BP motif of FBN1. There are now seven mutations affecting the TGF- $\beta 1$ BP motifs of this gene, of which only two (including $\mathrm{C} 711 \mathrm{Y}$ ) affect a cysteine residue. In both instances, it is the eighth cysteine of the respective TGF- $\beta 1 \mathrm{BP}$ motif that is substituted, suggesting that this particular cysteine may have a critical functional role within TGF- $\beta 1$ BP motifs. Elucidation of other similarly located mutations is needed to further our understanding of mutations within TGF- $\beta 1$ BP motifs of the FBN1 gene. The C1055G and $\mathrm{C} 1152 \mathrm{Y}$ mutations defined in the central portion of the gene add further credence to the growing evidence for mutations in this region and their association with a severe or neonatally lethal phenotype in Marfan syndrome.

We thank Professor G Sutherland for use of his laboratory facilities; K Friend, A Donnelly, J Gécz, and G Kremmidiotis for their technical expertise; and Drs D M Milewicz and H C Dietz for supplying aliquot parts for some of the primers used in this study. This research was supported by a Clinical Research this study. This research was supported by a Clinical Research Fellowship awarded to Dr L C Ades by the Women's and ChilCouncil support to Dr R I Richards.

1 Pyeritz RE, McKusick VA. The Marfan syndrome: diagnosis and management. N Engl f Med 1979;300:772-7.

2 Dietz HC, Pyeritz RE. Mutations in the human gene for fibrillin-1 (FBN1) in the Marfan syndrome and related disorders. Hum Mol Genet 1995;4:1799-809. 
3 Dietz HC, Ramirez F, Sakai LY. Marfan's syndrome and other microfibrillar diseases. In: Harris $\mathrm{H}$, Hirschhorn $\mathrm{K}$, eds. Advances in human genetics. Vol 22. New York: Plenum eds. Advances in hum.

4 Dietz HC, Cutting GR, Pyeritz RE, et al. Marfan syndrome caused by a recurrent de novo missense mutation in the fibrillin gene. Nature 1991;352:337-9.

5 Dietz HC, Saraiva JM, Pyeritz RE, Cutting GR, Francomano CA. Clustering of fibrillin (FBN1) missense mutations in Marfan syndrome patients at cysteine residues in EGF-like domains. Hum Mutat 1992;1:36674.

6 Kainulainen K, Pulkkinen L, Savolainen A, Kaitila I, Peltonen L. Location on chromosome 15 of the gene defect causing Marfan syndrome. N Engl f Med 1990;323:935-9.

7 Kainulainen K, Karrtunen L, Puhakka L, Sakai L, Peltonen L. Mutations in the fibrillin gene responsible for dominant ectopia lentis and neonatal Marfan syndrome. Nature ectopia lentis and

8 Milewicz DM, Duvic M. Severe neonatal Marfan syndrome resulting from a de novo 3 -bp insertion into the fibrillin gene on chromosome 15. Am f Hum Genet 1994;54:44753.

9 Francke U, Berg MA, Tynan K, et al. A Gly1127Ser mutation in an EGF-like domain of the fibrillin-1 gene is a risk factor for ascending aortic aneurysm and dissection. $A m \mathcal{F}$ Hum Genet 1995;56:1287-96.

10 Milewicz DM, Grossfield J, Cao S, Kielty C, Covitz W, Jewett T. A mutation in FBN1 disrupts profibrillin processing and results in isolated skeletal features of the Marfan syndrome. 7 Clin Invest 1995;95:2373-8.

11 Sakai LY, Keene DR, Engvall E. Fibrillin, a new 350 kD glycoprotein, is a component of extracellular microfibrils. glycoprotein, is a component of

12 Corson GM, Chalberg SC, Dietz HC, Charbonneau NL, Sakai LY. Fibrillin binds calcium and is coded by cDNAs that reveal a multidomain structure and alternatively spliced exons at the 5' end. Genomics 1993;17:476-84.
13 Maslen CL, Corson GM, Maddox BK, Glanville RW, Sakai LY. Partial sequence of a candidate gene for the Marfan syndrome. Nature 1991;353:334-7.

14 Niibroek G, Sood S, McIntosh I, et al. Fifteen novel FBN 1 mutations causing Marfan syndrome detected by heteroduplex analysis of genomic amplicons. Am $\mathcal{f}$ Hum Genet 1995;57:8-21.

15 Kogan SC, Doherty M, Gitschier J. An improved method for prenatal diagnosis of genetic diseases by analysis of amplified DNA sequences. N Engl F Med 1987;317:985-90.

16 Orita M, Suzuki Y, Sekiya T, Hayashi K. Rapid and sensitive detection of point mutations and DNA polymorphisms using the polymerase chain reaction. Genomics 1989 5:874-9.

17 Ford EB. The genetics of polymorphism in the lepidoptera. Adv Genet 1953;5:43-87.

18 Tynan $\mathrm{K}$, Comeau K, Pearson $\mathrm{M}$, et al. Mutation screening of complete fibrillin-1 coding sequence: report of five new mutations, including two in 8-cysteine domains. Hum Mol mutations, including two in

19 Aoyama T, Tynan K, Dietz HC, Francke U, Furthmayr H. Missense mutations impair intracellular processing of fibrillin and microfibril assembly in Marfan syndrome. Hum Mol Genet 1993;2:2135-40.

20 Maumenee IH. The eye in Marfan syndrome. Trans Am Ophthal Soc 1981;79:684-733.

21 Subirats-Bayego E, Vila-Subirana T, Torrents-Fernandez A, Sirvent-Sanchez S, Comas-Roses J. Sindrome de Marfan y hernia diafragmatica. Med Clin (Barc) 1983;29:597.

22 Karrtunen L, Raghunath M, Lönnqvist L, Peltonen L. A compound heterozygous Marfan patient: two defective fibrillin alleles results in a lethal phenotype. Am $\mathcal{f}$ Hum Genet 1994;55:1083-91.

23 Peltonen L, Karrtunen L, Rantamäki T, Lönnqvist L, Kielty C, Raghunath M, Sakai L. Consequences of fibrillin muta, Raghunath $M$, Sakai L. Consequences of fibrillin muta-
tions for fibril formation in Marfan syndrome. Third International Symposium on the Marfan Syndrome, Berlin, September 1994:Abst 35. 